\title{
THE EFFECT OF SPLENIC CONTRACTION ON THE FORMED ELEMENTS OF THE BLOOD IN A CASE OF ANEMIA AND SPLENOMEGALY
}

\author{
By D. K. MILLER AND C. P. RHOADS
}

(From the Hospital of the Rockefeller Institute for Medical Research, New York City)

(Received for publication June 17, 1933)

The function of the spleen as a reservoir for the formed elements of the blood is a comparatively recent conception. Experimental studies have dealt principally with the number of erythrocytes stored or static in the splenic pulp and have neglected other equally significant cellular elements. Such studies, moreover, have been almost entirely made upon animals and the application of the results to problems of human physiology has not been proven.

Stukeley (1) suggested in 1723 that the spleen manifested relaxation and active muscular contraction. Gray (2) in 1854 mentioned the function of the spleen as that of a "safety-valve" for the storage of blood apart from the general circulation. Roy was the first physiologist to observe the actual rhythmic movements and contraction of the spleen in laboratory animals (3). His work was confirmed in 1896 by Schäfer and Moore who also demonstrated the innervation of the organ (4). The present day views of the function of the spleen as a blood reservoir are largely due to the work of Barcroft and his associates (5). Barcroft brought the spleens of dogs out through a slit in the abdominal wall and left them in this position for considerable periods of time, protected only by saline dressings. With these preparations he demonstrated the rhythmic movements of the spleen and also the active contraction after various stimuli such as heat, exercise, and emotion. It was shown in later experiments that the spleen of the dog contracts to one-half or one-third of its normal size during exercise and to an even greater extent after severe hemorrhage or the death of the animal. His work with carbon monoxide has clearly demonstrated that the spleen serves as a reservoir of red blood corpuscles.

Many studies have been made on the hemoglobin content and the erythrocyte count of blood expelled from the spleen both during active contraction and while the organ was quiescent. Consistent results have not been obtained. In some cases identical values were obtained for blood from the splenic artery and vein. Cruickshank (6), working in Barcroft's laboratory, by cannulizing the inferior mesenteric vein, col- 
lected blood during contractions of the spleen. At the same time he measured the contraction of the spleen and the quantity of blood expelled. From experiments of this nature he determined that the blood expelled was often richer in hemoglobin than was the blood of the general circulation. The concentration of hemoglobin varied during the contraction, the maximum value being 20 to 40 per cent higher than that of the normal peripheral blood. The amount of blood expelled from the spleen by a single contraction was estimated to be 2.6 to 5.6 per cent of the total blood volume of the animal.

An opportunity for the detailed study of the spleen as a reservoir of blood was presented to us in a patient in which there was an anemia and splenomegaly. The spleen in this patient was easily demonstrable and could be visualized by the $\mathrm{x}$-ray. It was observed that the spleen invariably contracted following the intravenous injection of liver extract, a therapeutic measure instituted with a view to relieving the anemia. The present paper deals with the changes in the number and character of the formed blood elements which took place during the splenic contractions induced by this and other methods.

\section{METHODS}

The general plan was to study the character and cellular composition of the peripheral blood before and after the induced contraction of the spleen, and to compare these findings with the changes in the size of the organ, as determined by $\mathrm{x}$-ray.

Blood samples were taken by venipuncture both before and after the splenic contraction. The red and white corpuscles were enumerated in the usual way in these samples. Hemoglobin determinations were made by the Sahli acid hematin method, using calibrated tubes and standards. The mean corpuscular volume of the erythrocytes was determined with the Mintrobe hematocrit tube. Enumeration of the blood platelets was then done on blood obtained from a freely bleeding puncture of the ear lobe. Three per cent sodium citrate solution prepared freshly every day was used as a diluting fluid in the red corpuscle pipette. Great care was exercised to keep the sodium citrate solution and all the glassware free from dust and dirt. Fragility tests of the red corpuscles were done by the usual method, using sodium chloride solutions in dilutions varying from 0.52 to 0.28 per cent. Controls were made on normal bloods at each determination. Blood volume determinations by the vital red method of Rowntree (7) were made before and after splenic contractions. X-rays of the spleen were taken before the injection and at regular intervals following the contractions. The surface area of the splenic shadow was measured on these $x$-rays with a Keuffel and Esser planimeter. The upper pole of the spleen could not be definitely outlined: therefore identical points were taken on the ribs from which measurements were made.

\section{OBSERVATIONS}

Clinical summary. The patient, a 55 year old Puerto Rican woman, entered the hospital complaining of attacks of diarrhea and abdominal discomfort of four and a half years' duration. A diagnosis of sprue had been 
made fifteen years ago while the patient was a resident of Puerto Rico. Following her arrival in this country thirteen years ago the diarrhea ceased and the patient gained weight. There was no history of yellow fever, typhoid, or malaria.

The present illness began about four and a half years ago when the patient noticed five or six loose bowel movements a day. These attacks lasted about three weeks and occurred once or twice a year. An abdominal mass was noticed on the left side of her abdomen three years ago. Six months before entry the patient noticed shortness of breath and pallor. Three months later a local doctor found a severe anemia and transfused the patient. Following this the patient improved and was well until one month before entry, when her diarrhea and abdominal discomfort returned. At the same time her pallor was again noticed and she became short of breath on exertion.

Physical examination. The patient was markedly emaciated and had moderate pallor of her skin and mucous membranes. No lymphadenopathy was present. The heart and lungs were normal. The abdomen was moderately distended. A large, hard mass was palpated on the left side of the abdomen. The lower edge of the mass extended to the level of the umbilicus, the medial edge extended to the mid abdominal line. A notch was felt in this medial border. The red blood count was 3,240,000, hemoglobin 71 per cent, white cell count 1,250. The differential counts done with Wright's stained smears and by the supravital technique showed no abnormal cells. The fragility of the red blood cells was within normal limits. Gastric analysis showed no free hydrochloric acid after histamine expression.

For the treatment of the anemia liver extract was given intravenously. During the first injection, which was of twenty minutes' duration, the patient complained of severe abdominal pain, localized over the splenic area. Nausea and romiting promptly occurred. Toward the end of the injection marked flushing of the face, neck, hands, and arms was present. Immediately following the injection palpation of the abdomen revealed that the spleen, the lower edge of which had been just below the level of the umbilicus, had contracted in size until its lower edge was palpable about $1.0 \mathrm{~cm}$. below the costal margin. Moreover, whereas the spleen had been hard before injection, it was found to be very soft in consistency after the shrinkage in size. This observation suggested the studies reported in this communication. Table I represents a typical chronological protocol of these studies.

The results obtained in a typical study, using liver extract by intravenous injection as a stimulant to splenic contraction, are shown in Table II. From this table it is evident that without essential change in the total blood volume there was a significant increase in the formed elements of the blood following a shrinkage in the size of the spleen. Twenty-four hours later the spleen had practically regained its original size. Figure 1 presents tracings of the splenic shadow taken from the $\mathrm{x}$-rays and demonstrates the change of size of the spleen. The area of the spleen before injection was $90.3 \mathrm{sq}$. cm. Immediately after injection the spleen had contracted to an area of $32.3 \mathrm{sq} . \mathrm{cm}$. Accompanying this contraction there was an increase of 520,000 red blood cells in the erythrocyte count. The hemoglobin increased 15 per cent. At the same time even more marked rises were found in the white count and 
TARLE I

Chronological protocol

Time

Remarks

$2.45 \ldots \ldots$. . Palpation of abdomen reveals a firm, hard spleen, the lower edge of which is at the level of the umbilicus

$2.58 \ldots \ldots \ldots$. . . . . . . . of spleen

$3.00 \ldots \ldots \ldots$ First bleeding. Blood pressure: $120 / 70$

$3.03 \ldots . . . \ldots$. . Platelet count

$3.05 \ldots \ldots \ldots \ldots .11 .0 \mathrm{cc} .1 .5$ per cent vital red solution given intravenously

$3.09 \ldots \ldots \ldots$. . . . Bleeding for blood volume

$3.10 \ldots \ldots \ldots \ldots$ Injection of 10.0 cc. liver extract Eli Lilly (or $20 \mathrm{cc}$. Parke Davis) begun. Blood pressure: 122/68

$3.15 \ldots . . \ldots$. . Patient complained of severe pain in abdomen, headache, and nausea. No vomiting

$3.17 \ldots \ldots \ldots$ Marked flushing of face has occurred

$3.20 \ldots \ldots \ldots$. . . Blood pressure: $84 / 44$

$3.25 \ldots \ldots \ldots$. . Injection completed. Spleen palpable about $2.0 \mathrm{~cm}$. below the costal margin

$3.26 \ldots \ldots \ldots$. . . . . . . of spleen

$3.28 \ldots \ldots \ldots$. . . . . Bleeding

$3.30 \ldots \ldots$...... Platelet count

$3.38 \ldots \ldots \ldots \ldots 11.0 \mathrm{cc} .1 .5$ per cent vital red solution given intravenously

$3.42 \ldots \ldots \ldots$. . . . Bleeding for blood volume

$3.45 \ldots \ldots \ldots$. X-ray of spleen

24 hours later $x$-ray of spleen

the platelet count, the increase of the former being 950 cells and of the latter 74,000. Determination of the blood volume after contraction of the spleen showed an increase of the total blood volume of only $200 \mathrm{cc}$. With this the plasma volume decreased from 65 to 60 per cent. There was also a decrease in the total plasma volume. The fragility of the red cells to sodium chloride solutions was not altered after contraction of the spleen.

TABLE II

Effects of contraction of the spleen induced by liver extract

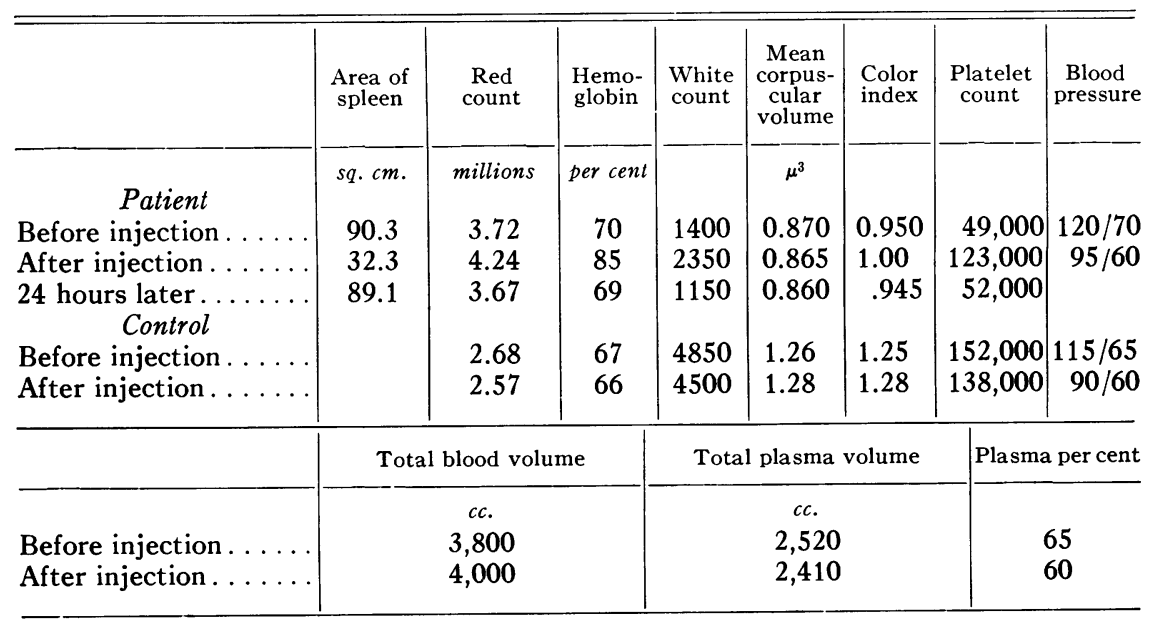




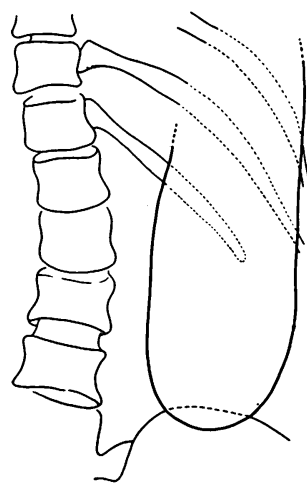

Before injection

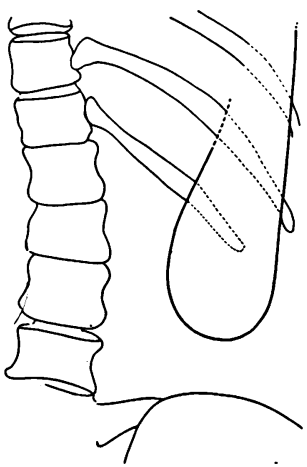

After injection

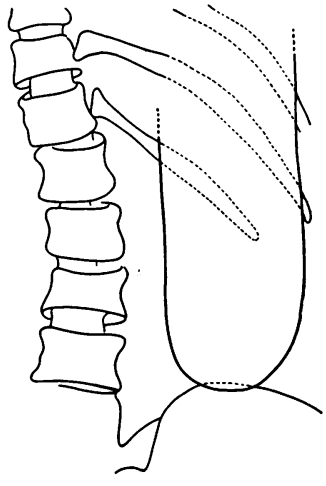

5 hours after injection

FIG. 1

Shows a series of tracings taken from the $x$-rays of the spleen demonstrating the size of the spleen immediately before the injection of liver extract, immediately after contraction had occurred, and 5 hours later, at which time the spleen had practically regained its original size.

A study of the formed elements of the blood following the injection of liver extract intravenously into a control patient with anemia, but without splenomegaly, is also included in Table II. It is evident from these results that there was no appreciable alteration in these elements following this injection. Results similar to those found in Table II have been obtained repeatedly following the intravenous injection of liver extract into the patient with splenomegaly. The degree of contraction of the spleen and the changes in the formed elements of the blood have varied directly with the degree of contraction obtained in each study. The observations presented here are neither the maximal nor the minimal results obtained, but are taken as the most typical.

The combined results of the alterations of the formed elements in the peripheral blood, obtained after induced splenic contraction in five studies in which liver extract was used as the stimulant, are presented in Table III. The average splenic contraction as shown was from a surface area of $93.6 \mathrm{sq} . \mathrm{cm}$. to an area of $50.0 \mathrm{sq} . \mathrm{cm}$. This is a decrease in the size of the spleen to 53 per cent of its original size. The average increase in the erythrocyte count after contraction was 500,000 red cells, or an increase of 13.9 per cent. Together with this the hemoglobin increase in this series was 10 per cent, or an average increase of 13.7 per cent of the original average hemoglobin value. The white blood cells showed an average increase of 840 cells, or average increase of 51 per cent. The blood platelets showed an average increase of 66,000 or of 105 per cent. It is apparent from this table that the relative increases were far greater for the white cells and the blood platelets than for the erythrocytes; this observation was seen in every study. 


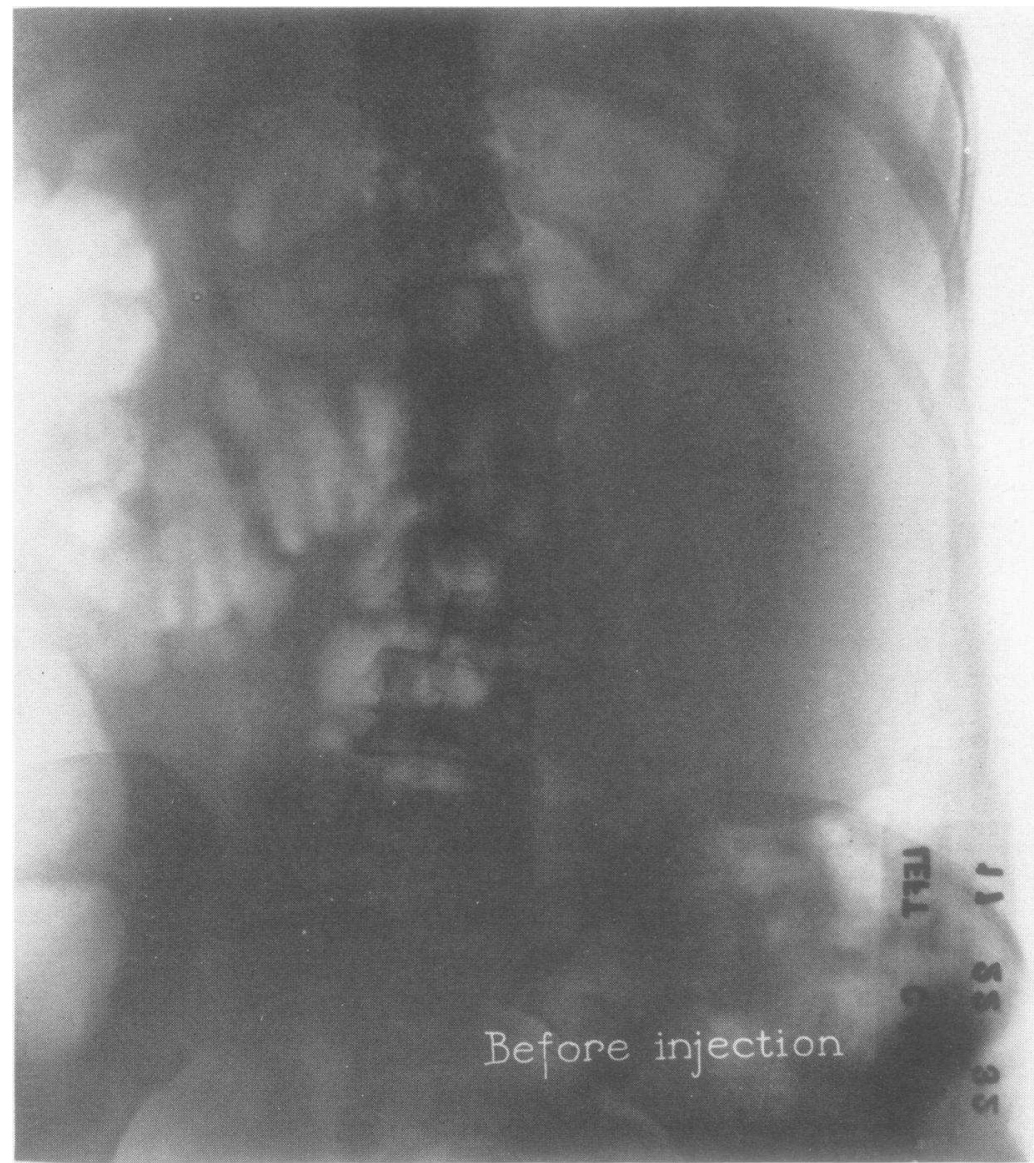

FIG. 2

This is an $x$-ray of the spleen taken immediately before the injection of liver extract. In this $\mathrm{x}$-ray the lower border of the spleen is seen beneath the crest of the ilium.

TABLE III

Combined studies of splenic contractions induced by liver extract

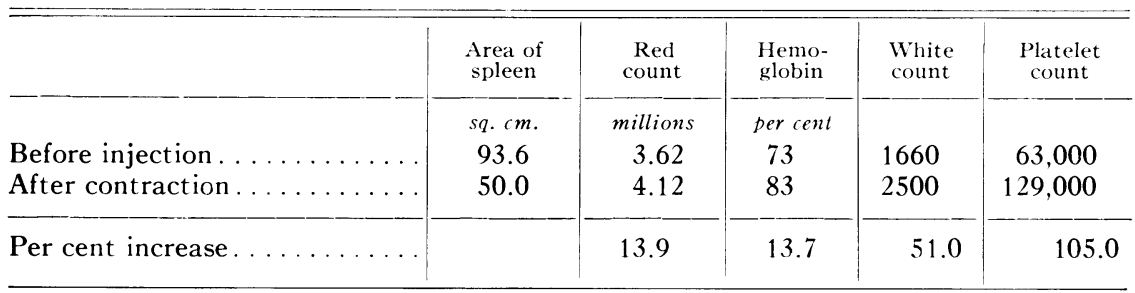

These observations suggested the possibility of attempting to evaluate on the human spleen the effects of certain drugs which have been known 


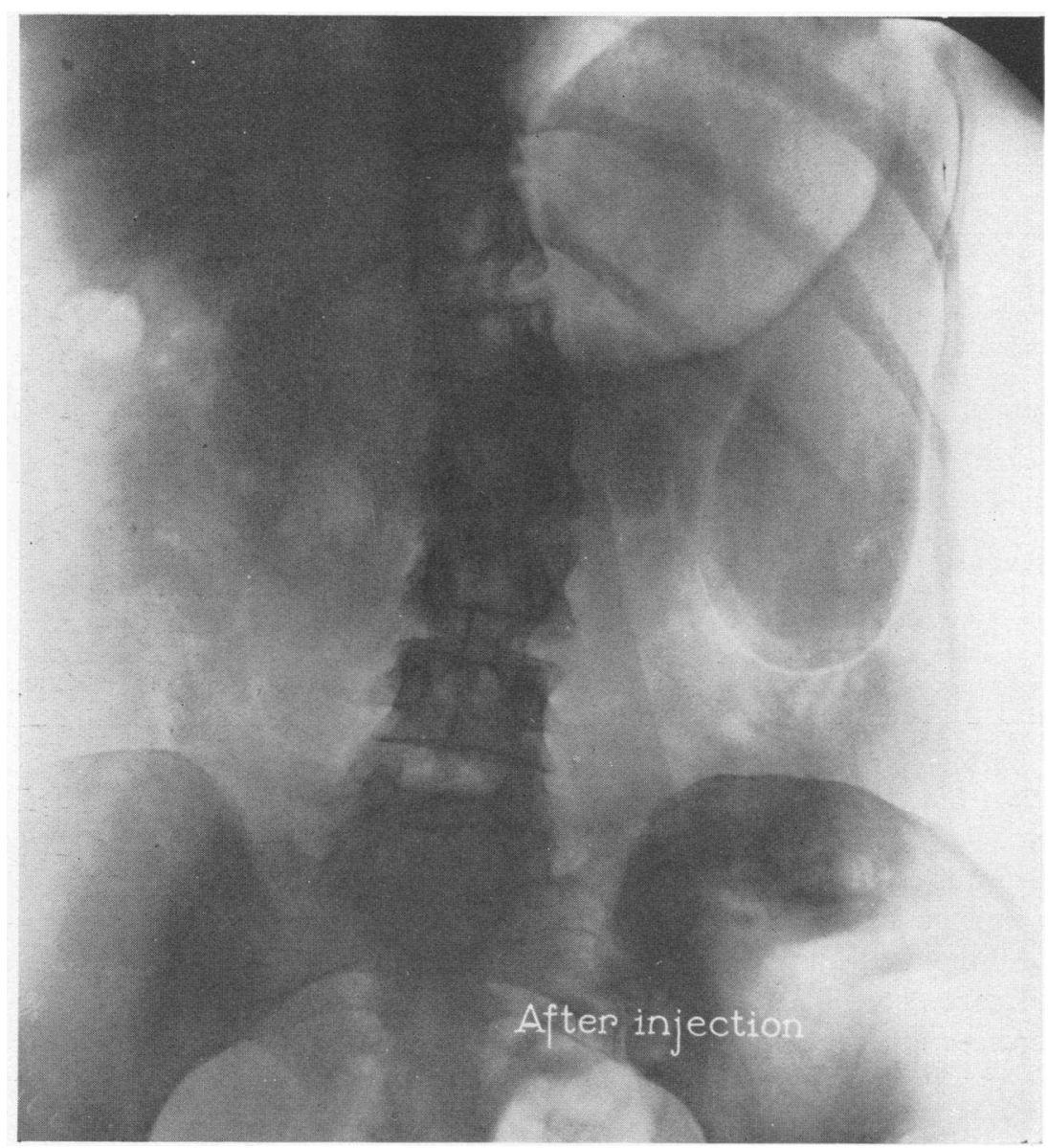

FIG. 3

This is an $x$-ray of the spleen taken immediately after the injection of liver extract, and demonstrates the change in size of the splenic shadow.

to stimulate splenic contractions in animals. Consequently, adrenalin, histamine, and eserine were used to induce splenic contractions. The results obtained following the intramuscular injection of these drugs are presented in Table IV.

As shown in the table a marked contraction of the spleen was noted eight minutes after the intramuscular injection of $1.0 \mathrm{cc}$. of adrenalin. The spleen contracted from an area of $109.0 \mathrm{sq}$. cm. to an area of 48.7 sq. cm. One hour later it had increased in size to $82.4 \mathrm{sq} . \mathrm{cm}$. Accompanying this contraction there was an increase in the red blood cell count of 650,000 cells, together with an increase of hemoglobin of 19 per cent. In this study the white blood rells showed the maximal increase obtained, 
TABLE IV

Effects of contraction of the spleen induced by adrenalin, histamine, and eserine

\begin{tabular}{|c|c|c|c|c|c|c|c|c|}
\hline & $\left|\begin{array}{l}\text { Area of } \\
\text { spleen }\end{array}\right|$ & $\begin{array}{l}\text { Red } \\
\text { count }\end{array}$ & $\begin{array}{c}\text { Hemo- } \\
\text { globin }\end{array}$ & $\begin{array}{l}\text { White } \\
\text { count }\end{array}$ & $\begin{array}{l}\text { Mean } \\
\text { corpus } \\
\text { cular } \\
\text { volume }\end{array}$ & $\begin{array}{l}\text { Color } \\
\text { index }\end{array}$ & $\begin{array}{l}\text { Platelet } \\
\text { count }\end{array}$ & $\begin{array}{l}\text { Blood } \\
\text { pressure }\end{array}$ \\
\hline Adrenalin & sq. $\mathrm{cm}$. & millions & spercent & & $\mu^{3}$ & & & \\
\hline Before iniection............ & 109.1 & 3.22 & 63 & 1500 & 0.917 & 0.985 & 90,000 & $124 / 75$ \\
\hline $\begin{array}{l}8 \text { minutes after injection of } \\
1 \text { cc., I.M. }{ }^{*} \ldots \ldots \ldots \ldots \ldots\end{array}$ & 48.7 & 3.87 & 79 & 4100 & 0.925 & 1.01 & 158,000 & $138 / 80$ \\
\hline $\begin{array}{c}1 \text { hour after injection } . . . \ldots \ldots \\
\text { Histamine }\end{array}$ & 84.2 & & & & & & & \\
\hline Before injection............. & 100.8 & 3.32 & 65 & 1650 & 0.915 & 0.985 & 68,000 & $122 / 78$ \\
\hline 1 mgm., I.M............ & 75.5 & 3.67 & 70 & 2700 & 0.915 & 0.960 & 124,000 & $106 / 52$ \\
\hline $\begin{array}{c}1 \text { hour after injection. . . . . . } \\
\text { Eserine }\end{array}$ & 93.5 & & & & & & & \\
\hline Before injection..$\ldots \ldots \ldots$ & 97.5 & 3.37 & 64 & 1250 & 0.900 & 0.955 & 96,000 & $128 / 70$ \\
\hline $\begin{array}{l}40 \text { minutes arter injection of } \\
2.4 \text { mgm., I.M............ }\end{array}$ & 73.6 & 3.36 & 64 & 1100 & 0.890 & 0.955 & 88,000 & $145 / 75$ \\
\hline
\end{tabular}

* I.M.-intramuscularly.

namely, 2,600 cells, or an increase of 172 per cent. With this contraction there was also an increase in the platelet count of 68,000 .

Splenic contraction was also induced by the intramuscular injection of $1.0 \mathrm{mgm}$. of histamine. Seven minutes after this injection the spleen had contracted from $100.8 \mathrm{sq} . \mathrm{cm}$. to $75.5 \mathrm{sq} . \mathrm{cm}$. In one hour it had increased in size to $93.5 \mathrm{sq}$. cm., that is, almost to its original size. With this contraction there was an increase in the red cell count of 350,000 red cells, with a 5 per cent increase of hemoglobin. The white blood cells increased by 1,050 cells and the platelet count was increased by 56,000 platelets. As in the previous studies the white blood cells and platelets showed a greater proportional increase than the red cells and the hemoglobin.

The intramuscular injection of $2.4 \mathrm{mgm}$. eserine sulphate also induced a splenic contraction. This contraction did not occur until 40 minutes after the injection. The surface area of the spleen decreased from 97.5 sq. $\mathrm{cm}$. to $73.6 \mathrm{sq} . \mathrm{cm}$. As seen in Table IV there was no appreciable alteration in the formed elements of the blood accompanying this contraction. This was the only study in which no significant alteration of the formed elements of the blood was obtained with an induced splenic contraction. When the parasympathetic nervous system was blocked by giving atropine intramuscularly no contraction followed the injection of eserine.

Differential blood counts are found in Table V. There was a relative and absolute increase in the polymorphonuclear cell count after the 


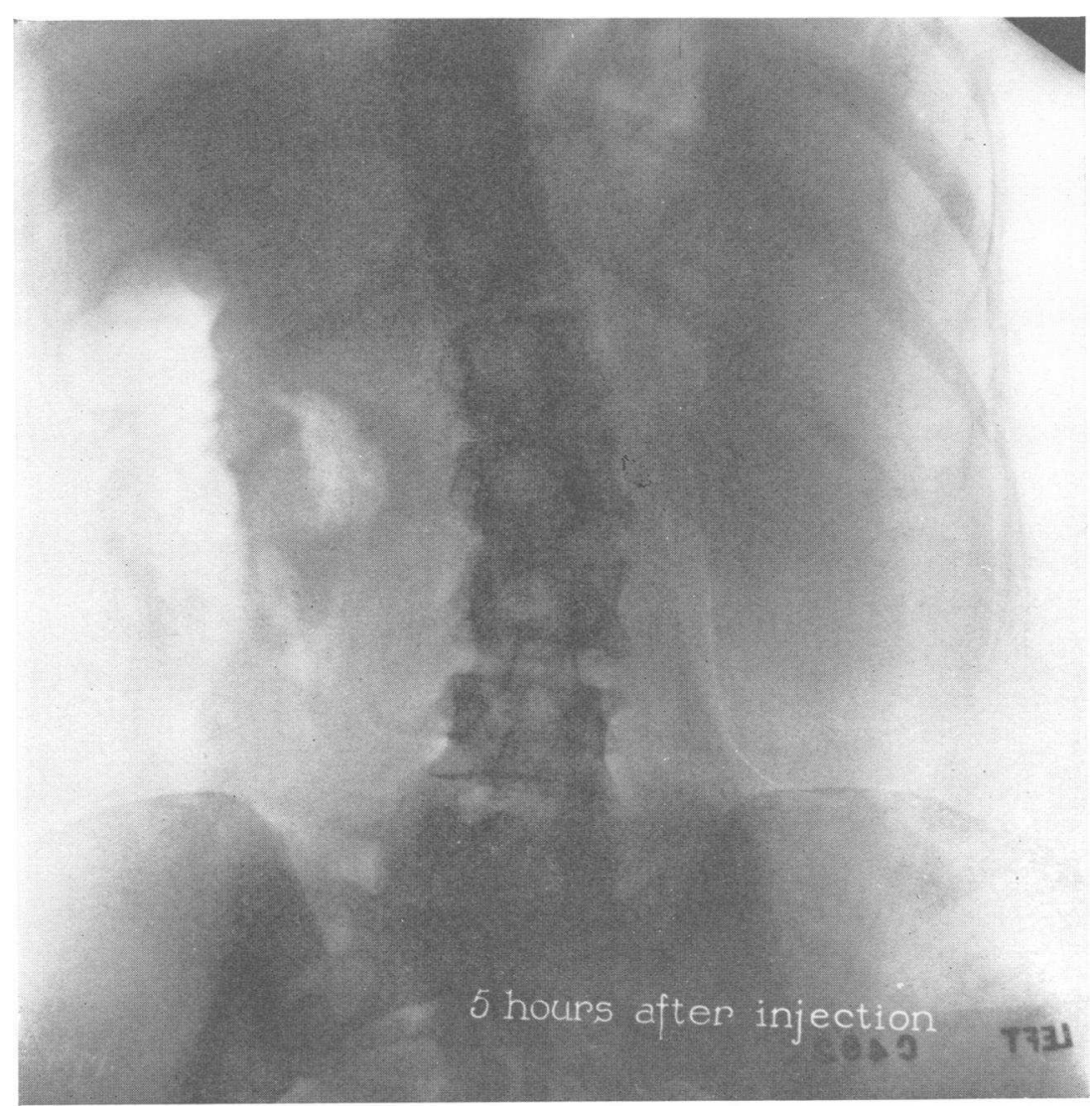

FIG. 4

This x-ray of the spleen was taken 5 hours after the contraction had occurred. It demonstrates the return of the spleen to its original size.

TABLE V

Differential white counts

\begin{tabular}{|c|c|c|c|c|}
\hline & \multicolumn{2}{|c|}{$\begin{array}{l}\text { Contraction induced by } \\
\text { liver extract }\end{array}$} & \multicolumn{2}{|c|}{$\begin{array}{l}\text { Contraction induced } \\
\text { by adrenalin }\end{array}$} \\
\hline & Before & After & Before & After \\
\hline & per cent & per cent & per cent & per cent \\
\hline Polymorphonuclears. . . . . . . . . & 46 & 72 & 44 & 57 \\
\hline Eosinophils . . . . . . . . . & & & & 1 \\
\hline Small lymphocytes. . . . . . . . & 51 & 22 & 52 & 37 \\
\hline Large lymphocytes. . . . . . . . . & 2 & 2 & 2 & 2 \\
\hline Monocytes......... & 1 & 4 & 2 & 3 \\
\hline
\end{tabular}


induced splenic contraction. Accompanying this there was a relative decrease in the lymphocyte count. These variations were found with each splenic contraction studied. No abnormal cells were seen in the smears taken either before or after the contraction. The reticulocyte count showed no variation.

The blood pressure was followed in each study, as may be seen in Tables II and IV. A fall in blood pressure was invariably obtained following the intravenous injection of liver extract. A similar fall of blood pressure occurred after the injection of histamine. In the studies in which adrenalin and eserine were used as the stimulant to contraction, there was invariably a rise in blood pressure.

\section{DISCUSSION}

Before discussing the data presented in this paper it may be well to point out that while certain changes in blood cytology took place as a result of the induced splenic contractions, the results may not be indicative of the function of the normal spleen, since it may be recalled that the patient showed both an anemia and a splenomegaly. Obviously such an abnormal organ could store a much greater quantity of blood or cells than could a spleen of normal size. Furthermore, the degree or ratio of contraction obtained could scarcely be expected to occur with the normal spleen. Thus it might be thought that the pathological conditions might negate or partially invalidate the significance of these observations as regards the normal physiological function of the organ as a blood reservoir. This matter cannot be definitely settled at this time, but the authors prefer the interpretation that the present circumstances constitute merely an exaggeration of the normal.

The mechanism of the contractions is not clearly understood. Dale and his co-workers (8) isolated histamine from alcoholic extracts of fresh liver. Histamine present in the liver extract given intravenously might then be the substance responsible for the induction of the splenic contraction. Similar effects, namely a splenic constriction, were produced with liver extract and with a drug stimulating the sympathetic nervous system, adrenalin. In these two types of experiments, there was a lowering of the blood pressure with the liver extract and a rise in blood pressure accompanying the contraction induced by adrenalin. This would seem to eliminate the fall in blood pressure as a significant occurrence. Furthermore, whereas there occurred a peripheral vasodilation in the study with liver extract, and a peripheral vasoconstriction in the contraction induced with adrenalin, it may be safely stated that peripheral vasodilation had little or no effect on the production of the alteration in the blood elements.

The contraction induced by histamine may have been due to the direct action of the drug on the unstriated musculature of the organ, or it may have been the response of the spleen to shock produced by the drug. 
A drug which stimulates the parasympathetic nervous system, namely, eserine, also gave a splenic contraction. It may be pointed out that the contraction was smaller than that obtained by other means, and that there was no alteration in the blood elements accompanying the change in size of the spleen.

Blood volume determinations showed very little alteration. There may have been at other times a greater increase in blood volume not detected by the method used. Vital red cannot be used repeatedly, intravenously, in clinical studies.

Perhaps the most striking fact among these results is the disproportionate increase in cell counts. Thus in each of the studies with liver extract and also with the other stimulating drugs the increase in the number of white blood cells was over threefold that of the red blood corpuscles, while the proportionate increase of the blood platelets was almost invariably greater than that of the white blood cells. No matter what mechanism was involved in the addition of these cells to the peripheral blood, these ratios may represent the relative proportions of these cells available in the splenic reservoir. This being the case the spleen may be considered as a potential and readily available source, not only of red blood corpuscles, but of white blood cells and blood platelets as well. It is not inconceivable that the spleen functions as a reservoir for these cellular elements.

\section{SUMMARY}

1. In a patient who showed both anemia and a splenomegaly it was possible to induce [and observe] a marked contraction of the spleen by the intravenous injection of liver extract, and the intramuscular injection of adrenalin, histamine, and eserine. This contraction was observed.

2. Accompanying these induced splenic contractions there occurred marked increases in the number of cellular elements of the circulating blood. The relative proportion of the various cellular components suggests that the blood of the splenic reservoir has a cytological composition in which the relative proportion of cells is different from that of the circulating blood.

3. These experiments make it obvious that the spleen must be considered not only as a reservoir of red blood cells, but that it can also store proportionally greater numbers of white blood cells and blood platelets.

\section{BIBLIOGRAPHY}

1. Stukeley, W., On the Spleen, Its Description and History, Uses and Diseases. London, 1723. Quoted by McNee, J. W., Lancet, 1931, i, 951. The Spleen: Its Structure, Functions and Diseases.

2. Gray, Henry, On the Structure and Use of the Spleen. Parker, London, 1854, p. 380.

3. Roy, C. S., J. Physiol., 1881, iii, 203. The Physiology and Pathology of the Spleen. 
4. Schäfer, E. A. and Moore, B., J. Physiol., 1896, xx, 11. On the Contractility and Innervation of the Spleen.

5. Barcroft, J. and Barcroft, H., J. Physiol., 1923, lviii, 138. Observations on the Taking up of Carbon Monoxide by the Hemoglobin in the Spleen.

Barcroft, J., Murry, C. D., Orahovats, D., Sands, J. and Weiss, R., J. Physiol., 1925, 1x, 79. The Influence of the Spleen in Carbon Monoxide Poisoning.

Barcroft, J., Lancet, 1925, i, 319. Recent Knowledge of the Spleen.

Barcroft, J. and Stephens, J. G., J. Physiol., 1927, liv, 1. Observations upon the Size of the Spleen.

Barcroft, J. and Nisimaru, Y., J. Physiol., 1932, 1xxiv, 299. Cause of Rhythmical Contraction of the Spleen.

6. Cruickshank, E. W. H., J. Physiol., 1926, lxi, 455. On the Output of Hemoglobin and Blood by the Spleen.

7. Rowntree, L. G. and Brown, G. E., The Volume of the Blood and Plasma in Health and Disease. W. B. Saunders Co., Philadelphia, 1929, p. 219.

8. Best, C. H., Dale, H. H., Dudley, H. W. and Thorpe, W. V., J. Physiol., 1927, lxii, 397. The Nature of the Vaso-Dilator Constituents of Certain Tissue Extracts. 